The Geneva Papers on Risk and Insurance, 17 (No. 64, July 1992), 314-321

\title{
Toward a Holistic Approach to Total Risk Management *
}

\author{
by Yacov Y. Haimes**
}

\section{Introduction}

Risk-based decision-making and risk-based approaches in decision-making are frequently used terms to indicate that some systematic process - in particular, one that deals with risk and the uncertainties associated with the problem at hand - is being used to formulate policy options and assess their various institutional impacts and ramifications. Today an ever-increasing number of professionals and managers in industry, government, and academia are devoting a larger portion of their time and resources to the task of improving their approach to, and understanding of, risk-based decision-making. In this pursuit they invariably rediscover (often with considerable frustration) the truism: the more you know about a complex subject, the more you realize how much still remains unknown. There are two fundamental reasons for the complexity of this subject. One is that decision-making under uncertainty literally encompasses every facet, dimension, and aspect of our lives. It affects us at the personal, corporate, or governmental level and during the planning, development, design, operation, or management phases. Uncertainty colors the decision-making process, whether it involves one or more parties, is constrained by economic or environmental considerations, is driven by socio-political or geographical forces, is directed by scientific or technological know-how, or influenced by various power brokers and stakeholders, or whether the process attempts to answer the set of questions posed by William W. Lowrance, "Who should decide on the acceptability of what risk, for whom, in what terms, and why?" The second reason risk-based decisionmaking is complex is that it is cross-disciplinary. The subject has been further complicated by the development of diverse approaches of varying reliability. Some methods, which on occasion produce fallacious results and conclusions, have become entrenched and would be hard to eradicate. To treat such a complex subject in a brief space, the discussion here will primarily focus on technological systems and the associated engineeringscientific staff personnel who work with such systems.

* This article is based on the following two editorials that appeared in Risk Analysis: An International Journal, Vol. 9, No. 2, 1989, and Vol. 11, No. 2, 1991, respectively: "Toward a Holistic Approach to Risk Assessment and Management" and "Total Risk Management". Reprinted by permission.

** Lawrence R. Quarles Professor of Engineering and Applied Science. Director, Center for Risk Management of Engineering Systems, University of Virginia, Charlottesville, VA 22903. 


\section{The holistic approach to risk analysis}

Good management of technological systems must address the holistic nature of the system in terms of its hierarchical, organizational, and functional decision-making structure; the multiple noncommensurate objectives, subobjectives, and sub-subobjectives including all types of important and relevant risks; the various time horizons; the multiple decision-makers, constituencies, power brokers, stakeholders, and users of the system; and the host of institutional, legal, and other socioeconomic conditions that require consideration. Thus, risk management raises several fundamental philosophical and methodological questions.

Shouldn't technological systems, with their unavoidable elements of risk and uncertainty, require that risk management be an integral part of technology management? If the answer to this question is yes, what does risk management mean when it is not practiced in the overall context of technology management, that is, when it is practiced only as an afterthought, a cosmetic gesture that lacks its perceived or intended effectiveness? And, if indeed engineering systems are almost always designed, constructed, and operated under conditions of risk and uncertainty and are often expected to achieve multiple and conflicting objectives, then shouldn't the identification, quantification, evaluation, and trading-off of risks, benefits, and costs constitute an integral and explicit component of the overall managerial decision-making process, not a separate, vacuous act? Or does this body of knowledge in risk assessment and management (which spans many disciplines and encompasses empirical, quantitative, and normative, judgmental aspects of decisionmaking) constitute a new discipline that is separate, say, from systems engineering/systems analysis? Or has systems engineering/systems analysis been too narrowly defined? When risk and uncertainty are addressed in a practical decision-making framework, has it been properly perceived that the body of knowledge known as risk assessment and management markedly fills a critical void that supplements and complements the theories and methodologies of systems engineering/systems analysis? Reflecting on these and other similar questions on the nature, role, and place of risk assessment and management (both in the management of technological systems and in the overall managerial decisionmaking process) should be much more than an exercise of intellectual curiosity. Rather, consideration of such questions should provide a way to bridge the gaps and remove some of the barriers that exist among the practitioners that come from almost every discipline.

Integrating and incorporating risk assessment and management of technological systems within the broader holistic approach to technology management also requires the reexamination of the concept of the expected outcome when it is used as the sole representation of risk. Many agree that in the expectation operation, commensuration of highfrequency low-damage and low-frequency catastrophic-damage events markedly distorts their relative importance and consequences as they are perceived, evaluated, and tradedoff by managers, decision-makers, and the public. Some are becoming more and more convinced of the grave limitations of the traditional and commonly used expected-outcome concept, and are complementing and supplementing the concept with conditional expectation, where decision criteria about extreme and catastrophic events are not averaged-out with more commonly occurring events. 


\section{The evolution of risk analysis}

In March 1961, Norbert Wiener, who is considered by many to be one of the fathers of what is known today as systems engineering, wrote the following in the Preface to the second edition of his book Cybernetics [1948]:

If a new scientific subject has real vitality, the center of interest in it must and should shift in the course of years... The role of information and the techniques of measuring and transmitting information constitute a whole discipline for the engineer, for the physiologist, and for the sociologist... Thus it behooves the cyberneticist to move on to new fields and to transfer a large part of his attention to ideas which have arisen.

Doesn't acceptance of the premise that good and appropriate technology management must be grounded on a holistic approach and of Wiener's philosophical and almost prophetic statements lead to the possibility that what we are witnessing today is a shift of the center of interest, an evolution toward a more holistic approach to management? Are we not seeing a convergence of a body of knowledge acquired by practitioners from diverse disciplines into a more coherent, though still heterogeneous, aggregate of theory, methodologies, tools, and heuristics? To highlight this evolutionary process, let us consider Wiener's "shift" from single-objective modeling and optimization to multipleobjective modeling and optimization.

During the past two decades the knowledge base of multiple objectives in modeling and decision-making has grown by leaps and bounds. The 1970s, in particular, have seen the emphasis shift from the dominance of single-objective modeling and optimization toward an emphasis on multiple objectives. This has led to the emergence of a new field that has come to be known as multiple-criteria decision-making (MCDM). MCDM has emerged as a philosophy that integrates common sense with empirical, quantitative, normative, descriptive, and value-judgment-based analysis. It is a philosophy that is supported by advanced systems concepts (e.g., data-management procedures, modeling methodologies, optimization and simulation techniques, and decision-making approaches) that are grounded on both the arts and the sciences for the ultimate purpose of improving the decision-making process. And indeed, multiple objectives are incorporated into most modeling and optimization of technological systems today. In this sense, MCDM has enhanced the management of technological systems and the managerial decision-making process by broadening the scope of the holistic approach. Can the same statement be made about the role of risk assessment and management in the overall holistic managerial approach? If the answer is yes, what are the corresponding pedagogical and pragmatic ramifications? And can our colleges and universities meet the challenges posed by this realization?

\section{The role of universities}

Very few engineering and applied science schools in the United States have acknowledged in their curricula the imperative need to respond to the complexity and the cross-disciplinary nature of risk assessment and management. Consequently, even fewer schools have considered extending and integrating courses in reliability, stochastic processes, and applied probability and statistics, taking them beyond mathematical rigor and into the art and science of decision-making under uncertainty. How many universities offer courses on the subject of risk assessment and management that integrate (a) new knowledge in the perception of risk and in the judgments associated with the acceptability 
of risk (e.g., the work of Slovic, Tversky, Kahneman), (b) the mathematics that help in the quantification of risk (e.g., the work of Bernoulli, Bayes, Savage), and (c) the holistic systems approach (e.g., the work of Russell, Wiener, von Neumann, Raiffa)? If the number of universities that incorporate such courses in their curricula is very limited, the questions are why and what are the long-term societal implications? Could we expect a less chaotic state of affairs in government and industry in their dealing with risk assessment and management, say a decade from now, if universities were to treat this subject in their curricula more seriously, methodically, and systematically? For example, could the study of risk be treated in the same way that systems engineering is being treated, as an important body of knowledge that every engineering student must acquire, either within the student's own department or discipline (e.g., at MIT) or as a separate department or discipline (e.g., at the University of Virginia)? Or is it too utopian to expect universities to initiate such a change in our approach to a more holistic framework? Indeed, although universities seem to be the most logical and natural place for educating such a cadre of cross-disciplinary professionals, present trends and evidence do not support this premise. Most university faculty members today are the prisoners of their own disciplines and the institutional departmental set-up. The present university system of rewards, including promotion and tenure, provides strong disincentives for change, especially if initiated by a young, developing faculty. Universities seem more likely to respond to government initiatives (when adequately funded) or follow the strong, emerging leadership of professional societies than to initiate and assume the leadership role themselves. Universities today seem to have lost some of their ability to identify urgent educational needs and build a pedagogical framework that is conducive to cross-disciplinary learning and growth; and with this, they have also lost some of their ability to pioneer responses to emerging societal challenges.

The thesis advanced here is not who should take the initiative for a more holistic pedagogical approach to risk assessment and management, whether it be universities, industry, government agencies, or professional societies and organizations. Rather, the argument is the urgent need for one or more of these parties to take such an initiative, lend the needed support for it, and provide the political will to ensure its realization. Only with such a long-term investment in the education of our new engineering and science students will we be able to expect an appropriate incorporation of risk assessment and management within a holistic management of technological systems and to achieve a more harmonious interplay and collaboration among the various science and engineering disciplines on this subject.

\section{Risk management}

To be effective and meaningful, risk management must be an integral part of the overall management of a system. This is particularly important in the management of technological systems, where the failure of the system can be caused by the failure of hardware, software, organization, or humans.

The term "management" may vary in meaning according to the discipline involved and/or the context. This is true also of risk, which is often defined as a measure of the probability and severity of adverse effects. Risk management is commonly distinguished from risk assessment, even though some may use the term risk management to encompass the entire process of risk assessment and management. In risk assessment the analyst 
often attempts to answer the following three questions [Kaplan and Garrick, 1981], what can go wrong? what is the likelihood that it would go wrong? and what are the consequences? Answers to these questions help risk analysts identify, measure, quantify, and evaluate risks and their consequences and impacts. Risk management builds on the risk assessment process by seeking answers to a second set of three questions: What can be done; what options are available and what are their associated trade-offs in terms of all costs, benefits, and risks; and what are the impacts of current management decisions on future options? Only when these questions are addressed in the broader context of management, where all options and their associated trade-offs are considered within the hierarchical organizational structure, can a total risk management (TRM) be realized. (The term TRM will be formally defined later.) Indeed, evaluating the total trade-offs among all important and relevant system objectives in terms of costs, benefits, and risks cannot be done seriously and meaningfully in isolation from the broader resource allocation perspectives of the overall organization. Good management must thus incorporate and address risk management within a holistic and all-encompassing framework that incorporates and addresses all relevant resource allocations and other related management issues. A total risk management approach that harmonizes risk management with the overall system management must address the following four sources of system failure:

(a) hardware failure

(b) software failure

(c) organizational failure

(d) human failure.

This set of sources of failure is intended to be internally comprehensive, i.e., comprehensive within the system's own internal environment. (External sources of failure are not addressed here because they are commonly system-dependent.) These four elements are not necessarily independent of each other, however. The distinction between software and hardware is not always straightforward, and separating human and organizational failure is often not an easy task. Nevertheless, these four categories of sources of failure provide a meaningful foundation upon which to build a total risk management framework. In his premier book on quality control, Kaizen [1986], Imai says, "The three building blocks of business are hardware, software, and 'humanware'". He further states that total quality control "means that quality control efforts must involve people, organization, hardware, and software". In her extensive research on the off-shore oil industry, Paté-Cornell [1990] found that organizational failures accounted for more than $90 \%$ of the accidents.

It is important to consider these four sources of failure for two reasons. The first is their comprehensiveness: they involve all aspects of a system's planning, design, construction, operation, and management. Of secondary importance is the total involvement in the risk assessment and management process of everyone concerned - from blue- and white-collar workers to managers at all levels of the organizational hierarchy. To ensure total quality control and productivity throughout the organizational structure, Deming [1990] advocates the appointment of a leader knowledgeable in statistical methodology, who reports directly to the president of the organization. Deming states:

He will assume leadership in statistical methodology throughout the company. $\mathrm{He}$ will have authority from top management to be a participant in any activity that in his judgment is worth his pursuit. He will be a regular participant in any major meeting of the president and his staff. 
Indeed total quality control (or total quality management) is very much commensurate and harmonious with total risk management. And total risk management builds on the concept of and experience gained from total quality control that is widely used in manufacturing. The Japanese definition of quality control according to the Japan Industrial Standards (z8101-1981) is [Imai, 1986]:

Implementing quality control effectively necessitates the cooperation of all people in the company, including top management, managers, supervisors, and workers in all areas of corporate activities such as market research and development, product planning, design, preparations for production, purchasing, vendor management, manufacturing, inspection, sales and after-services, as well as financial control, personnel administration, and training and education. Quality control carried out in this manner is called company-wide quality control or total quality control.

\section{Total risk management}

Total risk management (TRM) can be defined as a systemic, statistically based, and holistic process that builds on formal risk assessment and management (answering the previously introduced two sets of triplet questions for risk assessment and risk management) and addresses the set of four sources of failures within a hierarchical-multiobjective framework.

The term hierarchical-multiobjective framework can be explained in the context of TRM. Most, if not all, organizations are hierarchical in their structure and consequently in the decisionmaking process that they follow. Furthermore, at each level of the organizational hierarchy, multiple, conflicting, competing, and noncommensurate objectives drive the decisionmaking process. Thus, within the organization, there are commonly several sets of objectives, subobjectives, and sub-subobjectives corresponding to the levels of the hierarchical structure and to its various units or subsystems [Haimes et al., 1990]. At the heart of good management decisions is the "optimal" allocation of the organization's resources among its various hierarchical levels and its various subsystems. The optimal allocation is meant in the Pareto optimal sense, where trade-offs among all costs, benefits, and risks are evaluated in terms of hierarchical objectives (and sub-objectives) and in terms of their impacts on future options. Methodological approaches for such a hierarchical framework are discussed in Haimes et al. [1990].

\section{Risk measurement and trade-off analysis}

One of the most dominant steps in the risk assessment process is the quantification of risk, yet the validity of the approach most commonly used to quantify risk - its expected value - has received neither the broad professional scrutiny it deserves nor the hoped-for wider mathematical challenge that it mandates. The conditional expected value of the risk of extreme events (among other conditional expected values of risks) generated by the partitioned multiobjective risk method (PMRM) [Asbeck and Haimes, 1984] is one of the few exceptions. Risk is a measure of the probability and severity of adverse effects. When measured via its mathematical expected value and used as the sole risk measure, however, risk is likely to be grossly misinterpreted, thus leading to bad management decisions.

Let $P_{x}(x)$ denote the probability density function of the random variable $X$, where $X$ is, for example, the concentration of the contaminant trichloroethylene (TCE) in a groundwater system, measured in parts per billion (ppb). Then the expected value of the 
containment concentration (the risk of the groundwater being contaminated by TCE at an average concentration of TCE), is $E(x) p p b$. If the probability density function is discretized to $n$ regions over the entire universe of contaminant concentrations, then $E(x)$ equals the sum of the product of $P_{i}$ and $\mathrm{X}_{i}$, where $P_{i}$ is the probability that the ith segement of the probability regime has a TCE concentration of $X_{i}$. Integration (instead of summation) can be used for the continuous case. Note, however, that the expected-value operation commensurates contaminations (events) of low concentration and high frequency with contaminations of high concentration and low frequency. For example, events $X_{1}=2 \mathrm{ppb}$ and $X_{2}=20,000 \mathrm{ppb}$ with probabilities $P_{1}=0.1$ and $P_{2}=0.00001$, respectively, yield the same contribution to the overall expected value: (0.1) (2) + $(0.00001)(20,000)=0.2+0.2$. However, the relatively low likelihood of a disastrous contamination of the groundwater system with $20,000 \mathrm{ppb}$ of TCE cannot be equivalent, in the mind of the decisionmaker in charge of the integrity of the groundwater system, to the contamination at a low concentration of $0.2 \mathrm{ppb}$, even with a very high likelihood of such contamination. Due to its smoothing mathematical nature, the averaging function of the contaminant concentration in this example doesn't lend itself to prudent management decisions. This is because the expected value of risk doesn't accentuate the catastrophic events and their consequences, thus misrepresenting what would have been a perceived unacceptable risk.

It is worth noting that the number of "good" decisions managers make during their tenure is not the only basis for rewards, promotion, and advancement; rather, they are aware that they might be penalized for any disastrous decisions, no matter how few, made during their career. The notion of "not on my watch" clearly demonstrates the point. In this and other senses, the expected value of risk fails to represent a measure that truly communicates the manager's or the decisionmaker's intentions and perceptions. The conditional expected value of risk of extreme events generated by the PMRM, when used in conjunction with the (unconditional) expected value, can markedly contribute to the total risk management approach. In this case, the manager must make trade-offs not only between the cost of prevention of contamination of TCE vs. the expected value of such contamination, but also the cost of prevention of contamination vs. the conditional expected value of an extreme level of contaminant concentration with TCE. This dual multiobjective analysis provides the manager with more complete, factual, and lesssmoothed information about all viable policy options and their associated trade-offs.

In this sense, incorporating the risk of extreme events in the total risk management framework enhances the realism and the representativeness of the elements of risk in the overall management decision.

\section{Epilogue}

The comprehensiveness of total risk management makes the systemic assessment and management of risk tractable from many perspectives. Available theories and methodologies developed and practiced by various disciplines can be adopted and/or modified as appropriate for TRM. Fault-tree analysis, for example, which was developed for the assessment and management of risks associated with hardware, can and is being modified and applied to assess and manage all four sources of failure - hardware, software, organizational failure, and human failure. Hierarchical multiobjective trade-off analysis can and is being applied to risks associated with public works and the infrastructure. As the 
importance of risk is better understood and its analysis is incorporated within a broader and more holistic management framework, the following progress is likely to be made:

(a) The field of risk analysis will lose some of its current mystique, gain a wider recognition, and more closely merge with the fields of systems engineering, systems analysis, and operations research.

(b) The various disciplines that conduct formal risk analysis will find that they share more common ground in their risk assessment and management than ever before.

(c) As a by-product of (a) and (b) above, the field of risk analysis will advance by leaps and bounds as the professional community benefits from the synergistic contributions made in the area of risk assessment and management by the various disciplines engineering, environmental science, medical health care, social and behavioral sciences, finance, economics, etc.

(d) New measures of risk will likely emerge either as a substitution for or as a supplement and complement to the expected value of risk measure.

(e) Probably of most importance, government officials, other professionals, and the public at large will have more appreciation of, and confidence in, the process of risk assessment and management.

\section{REFERENCES}

ASBECK, E., and HAIMES Y. Y., "The Partitioned Multiobjective Risk Method", Large Scale Systems, Vol. 6, No. 1, pp. 13-38, 1984.

DEMING, W. Edwards, Out of the Crisis, MIT, Center for Advanced Engineering Study, Cambridge, MA., 1990.

HAIMES, Yacov Y., TARVAINEN, Kyosti, SHIMA, Takaski, and THADATHIL, Jacob, Hierarchical Multiobjective Analysis of Large Scale Systems, Hemisphere Publishing Corp., New York, 1990.

IMAI, Masaaki, Kaizen: The Key to Japan's Competitive Success, McGraw-Hill Publishing Company, New York, 1986.

KAPLAN, S., and GARRICK, B.J., "On the Quantitative Definition of Risk", Risk Analysis, Vol. 1, No. 1, 1981.

LOWRANCE, W., Of Acceptable Risk, William Kaufmann, Inc. Los Altos, California, 1976.

PATÉ-CORNELL, M.E., "Organizational Aspects of Engineering System Safety: The Case of Offshore Platforms", Science, Vol. 250, pp. 1210-1217, 1990.

WIENER, N., Cybernetics, second Edition, MIT Press, Cambridge, Mass., 1961. 